Professor Sayers from Birmingham is unrepentant. Other experimenters, he said at the symposium, paid too little attention to the problem of integrating their experiments into the satellite. Only the University of Sheffield was worried about possible interference from Birmingham; as a result, changes were made, and the Sheffield experiment has worked perfectly.

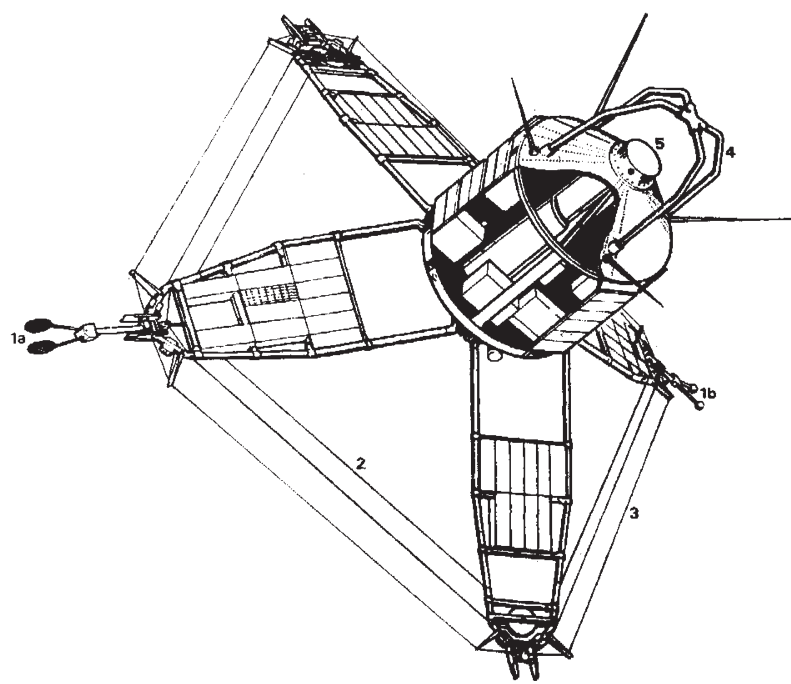

ARIEI, III SATELITLE. 1, University of Birmingham: $(a)$ electron density sensor; (b) electron temperature sensor. 2 , University of Sheffield: VLF loop antennae. 3, University of Manchester (Jodrel Bank): galactic noise loop antenna. 4, Radio and Space Research Station: terrestrial noise loop antennae. 5, Meteorological Office: oxygen distribution scanning mirror.

In all probability the interference could not have been predicted, except by testing the satellite with all experiments going in an ionized gas, a facility not available. A much simpler solution would have been to provide switching so that all the experiments could be turned on and off, instead of all operating all the time. NASA, which launched Ariel III for the Science Research Council, advised against this, because it increases complexity and all-up weight (Ariel III was already 25 per cent heavier than the target weight). Professor Sayers, however, believes that it would have been quite easy to switch off his experiment without increasing the number of commands. This is not the first time that interference of this sort has occurred, and clearly it would be convenient if experiments could be switched on and off. The British Black Arrow launcher should be able to offer more commands, space scientists hope.

\section{Waiting for Answers}

Authough the Austrian Government has now declared its willingness to participate in the construction of the $300 \mathrm{GeV}$ proton accelerator to be built within CERN, there is as yet no sign that the potentially important contributors to the cost of the project will make up their minds before the next meeting of the council of CERN, due to take place in Geneva on December 14. The British answer to the request by CERN for promises of contributions from the thirteen members of the organization is likely to come late in the day. Arrangements have apparently been made for a period of consultations within the Government, and it is unlikely that these will be completed much in advance of the timetable laid down by CERN. At the last meeting of the CERN council at the end of September, the British delegation raised the problem of how to modify the draft convention for the construction of the $300 \mathrm{GeV}$ machine in such a way that it would not be possible for countries making small contributions to the cost of the new machine to force an unwanted escalation of cost on the big subscribers. In the original version of the convention, as in the conventions which regulate the operation of the Meyrin Laboratory and of the proton storage rings which accompany it, the principle of one country one vote has been adopted. The British view that this might lead to irresponsible decisions in certain circumstances seems to have been accepted as an honest attempt to solve a common problem.

British fear of an escalation of cost seems to be shared by other European countries. At the last council meeting, the British delegation appears to have emphasized that its proposed contribution to the new CERN machine, estimated to amount to $£ 37.5$ million in the next ten years, is a substantial part of the annual budget of the Science Research Council. In circumstances like that, the argument goes, escalation would take funds from other fields of science and would for that reason be intolerable. So far, Belgium has agreed to participate, even on the original basis. So now has Austria. In spite of vigorous protestations of support by scientists among the French delegation to the CERN conference, however, there has so far been no official statement by the French authorities.

The eagerness the planners have shown has, however, been strengthened by reports of the speed with which the planning scheme under Professor R. Wilson for the $200 \mathrm{GeV}$ machine being built in the United States is making progress. It is also now known that the proton accelerator at Serpukhor has been operated successfully to produce protons at an energy of $75 \mathrm{GeV}$. This is somewhat greater than the maximum design energy of $70 \mathrm{GeV}$, but, at the extreme energies reached in the past weeks of commissioning, the intensity of the beam has been such that each pulse has produced $10^{8}$ protons-one-thousandth of the number of protons in a pulse when the machine is operating successfully. Full operation cannot be long delayed. In spite of the agreement between CERN and the Soviet Union that will give European physicists access to the Russian machine, the news from Serpukhov will no doubt strengthen the sense of deprivation at Geneva.

\section{European Physical Society}

AGREEMENT has been reached on the formation of a European Physical Society and it is planned that there should be an inaugural meeting in Florence in the last week of September 1968. This will be a fitting tribute to the enthusiasm of the Italians for the new venture and, in particular, to that of Professor G. Bernardini, who is chairman of the steering committee. The draft constitution of the proposed society, which has already been circulated to the councils of national physical societies, is to be discussed and-no doubtapproved at a meeting of the steering committee due to take place early in 1968 .

The view that the new society should begin as a loose federation will appeal not merely to those of 
Gaulist temperament but also to those who are aware of the practical problems of integrating the physics community. One obvious obstacle is the variation in the character of physical societies from one country to another. Another is the obscurity of many of the organizations which should properly play a part in the development of an integrated society. No doubt it will be several years before the various member societies have enough experience of each other's needs and interests for them to know which parts of their activities can be integrated and which will have to be kept going on a national basis. Until then, however, the organizers of the society see plenty of scope for constructive and common activity, principally in the organization of meetings. It will be interesting to see whether there are funds for financing exchange visits on a significant scale. The problems of journals have not apparently been tackled yet, although there seems to be a view that the ideal solution would be the specialization of existing journals in certain fields of physics. The official headquarters will probably be in Genera.

\section{New Trend in Teaching Science}

Is it possible to teach children engineering? This was the common question asked at the Institute of Electrical Engineers on October 12, when Mr G. B. Harrison, head of the department of creative design at Loughborough College of Education, opened a discussion entitled "The Influences of Changes in School Curricula on the Intake of Engineering Courses".

$\mathrm{Mr}$ Harrison, who is also director of the Schools Council engineering project, began by outlining the aims of the council, which helps children to understand what technology has to offer and trains them to meet the needs of growing up in a society dominated by technology. According to $\mathrm{Mr}$ Harrison, if technology is indeed accepted in schools, the traditional academic attitude of teachers will have to give way to the preparation of new material, apparatus, films, programmes and books that could be discarded when obsolete. He applauded the introduction of engineering as an A-level subject by five of the eight examining boards in the country, but is afraid that diversity might lead to confusion. A common A-level paper is essential so that universities, technical colleges and industry know what is being done at the schools.

An engineering science paper has been introduced by the Northern Universities Joint Matriculation Board to provide an alternative to physics which would meet university requirements. Although the syllabus is similar to traditional physics, it does include project work and practical exercises which demand design ability and creativity. The Oxford Examination Board also has an engineering course. This is, however, to be taken in addition to maths and physics in order to broaden the candidate's horizon. It includes the philosophy of engineering, design aspects and project work. The Cambridge course is essentially mechanical design but also includes the theory of structures and project work. Marks are awarded for project work and added as a bonus to the A-level physics mark. The value of all these courses will depend on the extent to which university courses are geared to work at school. According to $\mathrm{Mr}$ Harrison, the present flow from school to university is a series of acute mis-matches that can only be remedied by a long term reappraisal of the whole educational system.

In view of the importance of the topic, the discussion was sparsely attended, but there were several interesting points raised. Who, for example, is going to teach engineering in schools ? Certainly not the traditionally trained teachers who have passed through training college and who are often accused of being out of touch. Furthermore, as one speaker noted, this is not merely the age of technology, but of change in general: we are no longer living in a static society, and developments should be made in all directions without over-emphasizing any one particular aspect. There was general agreement that a new approach to education is needed and that the attitude of universities and technical colleges towards the acceptance of engineering as an A-level subject should be made clear. Obviously there are many arguments for and against the scheme, but several questions have yet to be answered. For example, have university students benefited by taking engineering at school? What evidence is there that children want technology and engineering in their general syllabus; have headmasters been approached by pupils anxious to study the additional subjects? Perhaps most important of all, has the introduction of engineering in the sixth form been reflected in the numbers reading engineering at establishments of further education? Why not have a census of opinion at all major schools to take into consideration the views of children themselves? All this may be clarified by the working paper, prepared by the Schools Council, which is shortly to be distributed.

\section{Indian Spoken Here}

THE proposed change of language in Indian education away from English prompted Mr Chagla, the Foreign Secretary, to resign early in September. The following week the proposal was discussed at the Conference of Vice-Chancellors in New Delhi, and although the resulting statement published afterwards is in agreement, it contains a certain amount of qualification.

The intention is that English should cease to be the centre of the higher education system, but its importance as a tool is not underestimated. School teaching is at present carried out in regional languages and it is hoped to extend this to undergraduate level. It is realized that a link language is essential, and that the need for a foreign language increases year by year, particularly for library study. Postgraduate courses will continue to be based on English, as translation of books and journals at this level would be impossibly expensive. Regional universities could work on this basis, but all-India institutions raise another problem. Hindi is at present spoken by 40 per cent of the Indian population, but there are some states that are actively against it. Any decision to use it as the education medium in national establishments would therefore have to be made with agreement from non-Hindi states. It is also realized that in multi-lingual cities English may have to be retained as the education medium, alongside the regional languages. The speed and nature of the changes are expected to vary from one university to another, according to circumstances, but undergraduate courses should not take more than 10 years to be adapted. 